\title{
Level and congener profiles of polybrominated dibenzo-p-dioxins and dibenzofurans in the atmosphere of Beijing, China
}

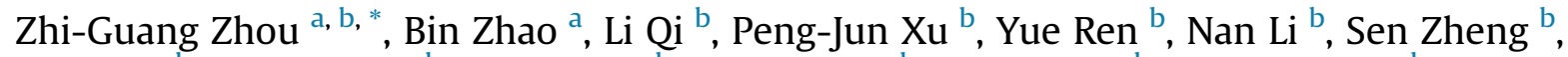 \\ Hu Zhao ${ }^{\mathrm{b}}$, Shuang Fan ${ }^{\mathrm{b}}$, Hui Zhang ${ }^{\mathrm{b}}$, Ting Zhang ${ }^{\mathrm{b}}$, Ai-Min Liu ${ }^{\mathrm{b}}$, Ye-Ru Huang ${ }^{\mathrm{b}}$ \\ a State Key Laboratory of Environmental Chemistry and Ecotoxicology, Research Center for Eco-Environmental Sciences, Chinese Academy of Sciences, \\ Beijing 100085, China \\ b State Environmental Protection Key Laboratory of Dioxin Pollution Control, National Research Center for Environmental Analysis and Measurement, 1 \\ South Yuhui Rd, Chaoyang District, Beijing 100029, China
}

\section{H I G H L I G H T S}

- Level and congener profiles of PBDD/Fs were researched at six sites in Beijing.

- Spatial distribution, seasonal variations were also researched.

- Studied the characteristics of PBDD/Fs in haze.

- We assessed the inhalation risk for residents in Beijing.

\section{A R T I C L E I N F O}

\section{Article history:}

Received 4 May 2014

Received in revised form 18 June 2014

Accepted 19 June 2014

Available online 19 June 2014

\section{Keywords:}

PBDD/Fs

Beijing

Atmosphere

Daily inhalation doses

\begin{abstract}
A B S T R A C T
Air samples were collected from six locations during the periods of February, 2011-March, 2012 in Beijing city. PBDD/Fs were analyzed using HRGC-HRMS. The concentrations, congener profiles, spatial distribution, seasonal variation, and inhalation risk assessment were investigated. The mass concentrations of 2,3,7,8-substituted PBDD/Fs is $818-5748 \mathrm{fg} \mathrm{m}^{-3}$ with an average of $2490 \mathrm{fg} \mathrm{m}^{-3}$. The highest concentration was observed at site XS in February, 2011 and the lowest was at site BS in July 2011. The

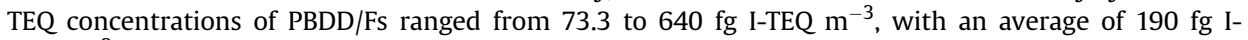
TEQ $\mathrm{m}^{-3}$. The dominant contributor to total I-TEQ value is $2,3,4,7,8-\mathrm{PeBDF}$, with an average contribution of $35 \%$. The PBDD/Fs at six sampling sites did not show obvious spatial variation. The concentration exhibits obvious seasonal variation, so atmospheric PBDD/F concentrations at six sample sites were much higher in winter than in summer. Residents in Beijing were exposed to PBDD/Fs with the daily inhalation

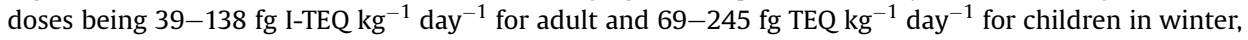
but in summer, the values were 10-33 for adult and 18-59 for children. The rough inhalation risk evaluation showed that the residents in Beijing had relatively higher exposure levels of $\mathrm{PBDD} / \mathrm{Fs}$ in winter, so more research about PBDD/Fs should be carried out at once.
\end{abstract}

๑) 2014 Elsevier Ltd. All rights reserved.

\section{Introduction}

Persistent halogenated organic pollutants, such as polychlorinated and polybrominated dibenzo-p-dioxins (PCDDs/ PBDDs), dibenzofurans (PCDFs/PBDFs), biphenyls (PCBs/PBBs), and diphenyl ethers (PCDEs/PBDEs), are widespread in the environment. Among such pollutants, polychlorinated compounds (including PCDD/Fs and PCBs) have been detected in emissions

\footnotetext{
* Corresponding author. State Environmental Protection Key Laboratory of Dioxin Pollution Control, National Research Center for Environmental Analysis and Measurement, 1 South Yuhui Rd, Chaoyang District, Beijing 100029, China.

E-mail address: zzguang2004@hotmail.com (Z.-G. Zhou).
}

from waste combustion, chemical plants, thermal sources, and workplace environments (Alcock et al., 1998; Lohmann et al., 2001; Shih et al., 2006; Mari et al., 2008). PBDD/Fs, which are PCDD/F analogs with all chlorine atoms substituted by bromine (WHO, 1994), have received less concern than PCDD/Fs, and data about their environmental level are very scarce. Up to now, $\mathrm{PBDD} / \mathrm{Fs}$ have been identified and determined in several matrices including: ambient air in Kyoto (Hayakawa et al., 2004), Osaka (Ohta et al., 2002; Watanabe et al., 1995), Shanghai (Li et al., 2008) and at different locations in Taiwan (Wang et al., 2008), at electronic waste dismantling areas in China (Li et al., 2007), in plastics from waste TV sets (Tasaki et al., 2004), as a constituent of flue gases (Wang and 


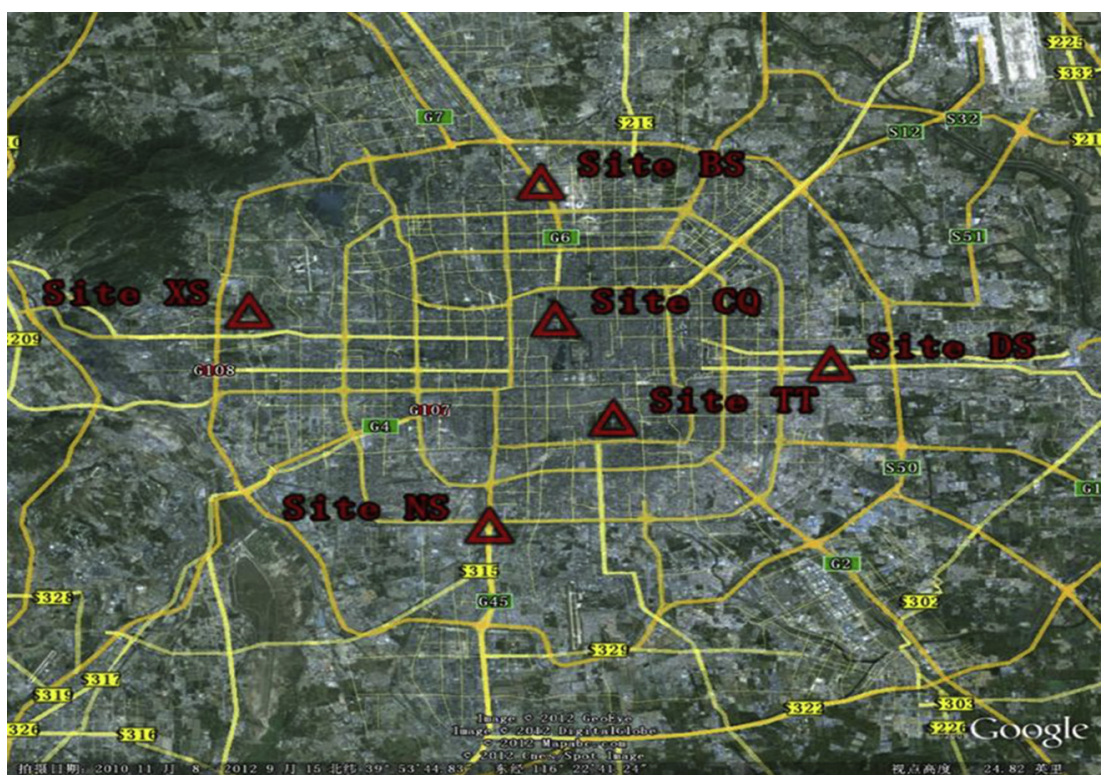

Fig. 1. Maps of sampling sites in Beijing.

Chang-Chien, 2007; Schüler and Jager, 2004), fly ash (Weber and Kuch, 2003; Hagberg et al., 2005; Sovocool et al., 1989; Schwind et al., 1988), sediments (Watanabe et al., 1995; Choi et al., 2003a,b; Hagberg et al., 2005), diet samples (Nomura et al., 2007), shellfish (Fernandes et al., 2008), fish (Ashizuka et al., 2008), adipose tissue (Choi et al., 2003a,b), human milk (Ohta et al., 2002), and blood from people with occupational exposure (Zober et al., 1992). Concerns about PBDD/Fs have increased because brominated flame retardants (BFRs) are extensively used in a variety of materials and are miscible with most plastics. Several potential routes for the release of $\mathrm{PBDD} / \mathrm{Fs}$ into the environment have been proposed, including formation in the process of manufacturing BFRs, formation during the processing of BFRs with polymer resin, and incinerating waste which contains BFRs (Thoma et al., 1987; Sakai et al., 2001; Hanari et al., 2006). Moreover, PBDD/ Fs can be transported over long distances from their sources of emission. Ambient air is the most important pathway for transfer of PBDD/Fs. Only a few studies exist, with little information on these brominated dioxins in the atmospheric environment (Hayakawa et al., 2004; Watanabe et al., 1995, 1992; Ohta et al., 2002).

Beijing is the capital of China, located on Huabei plain with area of $16,410 \mathrm{~km}^{2}$. It is also the biggest city in the country. Beijing belongs to the sub-humid warm temperate continental monsoon climate zone. The main industries include electronics, automobile manufacture, pharmaceutical synthesis and petroleum refining. Rapid economic growth and urbanization in recent years have sharply increased annual fossil fuel consumption in Beijing, resulting in air pollution which is sometimes severe.

This study is the first to monitor 2,3,7,8-substituted PBDD/Fs at six different functional zones in urban Beijing. Monitoring was carried out in winter, spring, summer and fall from February 2011 to March 2012. PBDD/F concentrations, profiles and their relationship with meteorological conditions, spatial distribution, seasonal variations, as well as inhalation risk assessment were investigated.

\section{Materials and methods}

\subsection{Sampling}

Six sampling sites covering six different functional zones were selected to evaluate the atmospheric levels and profiles of PBDD/Fs in Beijing. They were: Dongsi Road (DS: newly developed commercial area), Beisi Road (BS: culture area), Xisi Road (XS: old industrial area), Nansi Road (NS: traffic center), Changqiao (CQ: residential area), Tiantan (TT: urban resort area). The sampling locations, as well as the relevant landmarks, are indicated in Fig. 1. Site DS was about seven kilometers away from a power plant burning municipal solid waste, and site XS was about three kilometers away from the Babaoshan funeral parlor. Details about sampling date, sites, volume and target analytes in each sample are listed in Supplementary information Table S1.

Ambient air samples were collected using a SIBATA HV-1000F sampler, equipped with a quartz fiber filter (QFF), and followed by a glass cartridge containing two polyurethane foam (PUF) plugs. About $2160 \mathrm{~m}^{3}$ of ambient air were collected during a 72-h period, with a flow rate of $0.50 \mathrm{~m}^{3} \mathrm{~min}^{-1}$ and sampled twice at one site. The QFF was weighed before and after sampling to obtain total suspended particle (TSP) weight.

\subsection{Analysis}

\subsubsection{Chemicals}

All the organic solvents are pesticide residue grade from J. T. Baker (PA, USA). Silica gel was purchased from Wako (Osaka Japan). Calibration standard solutions, ${ }^{13} \mathrm{C}_{12}$ labeled clean-up standards and ${ }^{13} \mathrm{C}_{12}$ labeled injection standards were purchased from Wellington Laboratories (Guelph, Canada).

\subsubsection{Extraction and cleanup}

QFFs and PUFs were extracted and cleaned up separately. The analysis of PBDD/Fs followed the US EPA Method 1613 and Compendium Method TO-9A. Samples were extracted with toluene for $24 \mathrm{~h}$, and then the extract was sequentially cleaned using multilayer silica gel column chromatography $\left(\mathrm{H}_{2} \mathrm{SO}_{4}-\right.$ silica/KOH-silica) and activated carbon. The final elution was concentrated to $20 \mu \mathrm{L}$ under gentle nitrogen flow, and then injection standards were added for PBDD/Fs measurements. In this paper, the concentrations were the sum of PBDD/Fs in the vapor- and particle-phases.

\subsubsection{Instrumental analysis}

An Agilent $6890 \mathrm{~N}$ gas chromatograph connected with a Waters AutoSpec Ultima NT high - resolution mass spectrometer was 
Table 1

Comparison of PBDD/Fs levels with other urban studies.

\begin{tabular}{|c|c|c|c|c|}
\hline Site & Period & Type & I-TEQ $\left(\mathrm{fg} \mathrm{m}^{-3}\right)$ & Reference \\
\hline Germany & 1998 & $\begin{array}{l}\text { Motorway tunnel } \\
\text { Urban area } \\
\text { Suburban area }\end{array}$ & $\begin{array}{l}700-22,300 \\
80-1970 \\
\text { n.d. }-3400\end{array}$ & WHO (1998a,b) \\
\hline Taiwan & Not available & Recycle center & $3500-6700$ & WHO (1998a,b) \\
\hline Osaka Japan & 2001 & Urban area & 36 & Ohta et al. (2002) \\
\hline Kyoto Japan & $2000-2001$ & Urban area & $1760-12,100$ & Hayakawa et al. (2004) \\
\hline Guiyu China & 2005 & Area of near Guiyu & $\begin{array}{l}(8120-38,600)^{\mathrm{a}} \\
(23,200-461,000)^{\mathrm{b}}\end{array}$ & Li et al. (2007) \\
\hline Shanghai China & 2006 & $\begin{array}{l}\text { New developing area } \\
\text { Commercial area } \\
\text { Residential area } \\
\text { Industrial area }\end{array}$ & $\begin{array}{l}66-4160 \\
32-1960 \\
161-2600 \\
264-2670\end{array}$ & Li et al. (2008) \\
\hline Guangzhou China & 2004-2005 & $\begin{array}{l}\text { Background area } \\
\text { Suburban area } \\
\text { Urban area } \\
\text { Industrial area }\end{array}$ & $\begin{array}{l}57-393 \\
143-1470 \\
227-1720 \\
412-4170\end{array}$ & Li et al. (2011),c \\
\hline Taiwan & 2004-2005 & $\begin{array}{l}\text { Rural area } \\
\text { Urban area } \\
\text { Industrial area }\end{array}$ & $\begin{array}{l}3-20 \\
15-30 \\
28-58\end{array}$ & Wang et al. (2008) \\
\hline
\end{tabular}

employed. Samples were injected in splitless mode at an injector temperature of $300^{\circ} \mathrm{C}$. For separation of PBDD/Fs, a DB-5HT column $15 \mathrm{~m} \times 0.25 \mathrm{~mm}$ (film thickness $0.10 \mu \mathrm{m}$ ) was used. Oven temperature: $130{ }^{\circ} \mathrm{C}(2.0 \mathrm{~min})-230^{\circ} \mathrm{Cat} 30^{\circ} \mathrm{C} \mathrm{min}^{-1}, 230{ }^{\circ} \mathrm{C}-325^{\circ} \mathrm{C}$ (3.0 $\mathrm{min}$ ) at $10^{\circ} \mathrm{C} \mathrm{min}^{-1}$. Carrier gas: helium $\left(0.8 \mathrm{~mL} \mathrm{~min}^{-1}\right)$.

\subsection{Quality assurance and quality control $(\mathrm{QA} / \mathrm{QC})$}

A breakthrough test was performed using another PUF in series with the sampling PUF. None of the analyte was detected in the second PUF, indicating no breakthrough occurred in the sampling procedures. Each of all the samples was spiked with nine ${ }^{13} \mathrm{C}_{12^{-}}$ labeled internal standards of $\mathrm{PBDD} / \mathrm{Fs}$ to evaluate the cleanup procedures. The recoveries of all the labeled compounds were $51-109 \%$ for PBDD/Fs. One field and one laboratory blank were analyzed for every ten samples to check for interferences and laboratory contamination. The values were all below the detection limits (LODs) in the blanks. Detection limits were calculated by three times of signal-to-noise ratio, and the limits of method was $60 \mathrm{fg} \mathrm{m}^{-3}$ for $2,3,7,8-\mathrm{TBDF}, 12 \mathrm{fg} \mathrm{m}^{-3}$ for $1,2,3,7,8-\mathrm{PeBDF}, 8 \mathrm{fg} \mathrm{m}^{-3}$ for $2,3,4,7,8$-PeBDF, $11 \mathrm{fg} \mathrm{m}^{-3}$ for $1,2,3,4,7,8$-HxBDF, $50 \mathrm{fg} \mathrm{m}^{-3}$ for 1,2,3,4,6,7,8-HpBDF, $62 \mathrm{fg} \mathrm{m}^{-3}$ for OBDF, $4 \mathrm{fg} \mathrm{m}^{-3}$ for 2,3,7,8-TBDD, $7 \mathrm{fg} \mathrm{m}^{-3}$ for $1,2,3,7,8-\mathrm{PeBDD}, 14 \mathrm{fg} \mathrm{m}^{-3}$ for $1,2,3,4,7,8 / 6,7,8-\mathrm{HxBDD}$, $14 \mathrm{fg} \mathrm{m}^{-3}$ for $1,2,3,7,8,9-\mathrm{HxBDD}, 58 \mathrm{fg} \mathrm{m}^{-3}$ for OBDD.

\section{Results and discussion}

\subsection{Concentrations and profiles of $P B D D / F s$}

Compared to the PCDD/Fs, only 12 of the possible $2,3,7,8$ substituted PBDD/Fs were detected because of limitation of standard compounds. The mean values were calculated at each sample sites, and concentrations below the detection limits were regarded as zero. All the detailed information is summarized Table S1 (see in Supplementary information).

For all the samples, the mass concentrations of 2,3,7,8substituted PBDD/Fs is $818-5748 \mathrm{fg} \mathrm{m}^{-3}$ with an average of $2490 \mathrm{fg} \mathrm{m}^{-3}$. The highest concentrations were observed at site XS in February, 2011 and the lowest were at site BS in July 2011. The PBDFs were more dominant than PBDDs in all atmospheric environments, similar to Kyoto in Japan (Hayakawa et al., 2004). The main contributors to the $\sum$ PBDD/Fs were $1,2,3,4,6,7,8-\mathrm{HpBDF}$, 1,2,3,4,7,8-HxBDF, and 2,3,7,8-TBDF, which account for $40 \%, 14 \%$ and $11 \%$ on average, respectively. Table 1 summarizes the PBDD/F concentrations in ambient air in other cities. In comparison, the ambient air near special sources had higher PBDD/F levels than general urban areas and remote/background areas. This also was found in our study. Comparatively, PBDD/F in our study in Beijing were higher than in urban areas of Germany (WHO, 1998a,b) and Taiwan (Wang et al., 2008), but lower than Osaka, Japan (WHO, 1998a,b) and other special emission sources, such as Guiyu in China (Li et al., 2007).

A haze occurred on February 22-24 in 2011 during the sample period, which suggested heavy air pollution, according to the data released by the Beijing Environmental Monitor Station. PM $_{10}$ ranged from 160 to $270 \mu \mathrm{g} \mathrm{m}^{-3}$ (the second class air quality value: $150 \mu \mathrm{g} \mathrm{m}^{-3}$ ). During the haze period, the level of PBDD/Fs increased dramatically with the highest mass concentration of $5748 \mathrm{fg} \mathrm{m}^{-3}$, which is about five times higher than those during non-haze periods. In the following four days, the concentration of PBDD/Fs decreased to about one fifth of the highest concentration, with snow occurring. When haze occurred, the TSP concentration increased by two times, while the concentration of PBDD/Fs increased by five times. Other studies reported that fine particles increase in haze, and fine particles have larger specific surface area and therefore absorbed more PCDD/Fs, so the concentration of PCDD/Fs increased more than TSP (In and Park, 2003; Ohta et al., 2002).

Although, PBDD/Fs and PCDD/Fs have different physicochemical properties and geochemical behavior in the environment, perhaps absorbed by fine particles is consistent, so PBDD/Fs increased more than TSP in haze.

\subsection{I-TEQ concentrations of PBDD/Fs}

Because the toxic equivalency factors (TEFs) have not been determined for PBDD/Fs, the I-TEFs of PCDD/Fs were used for the corresponding congeners of PBDD/Fs to calculate their toxicities in the atmosphere (WHO, 1998a,b). The I-TEQ concentration of PBDD/ Fs ranged from 73.3 to $640 \mathrm{fg}$ I-TEQ $\mathrm{m}^{-3}$, with an average of $190 \mathrm{fg} \mathrm{I-}$ TEQ $\mathrm{m}^{-3}$. The dominant contributor to total I-TEQ value is $2,3,4,7,8-$ PeBDF, with an average contribution of $35 \%$. Other important 
contributors were 1,2,3,4,7,8-HxBDF (19\%), 1,2,3,7,8-PeBDD (15\%), 2,3,7,8-TBDF (14\%). 1,2,3,4,7,8/6,7,8-HxBDD, 1,2,3,7,8,9-HxBDD and OBDD contribute $<1 \%$ to the I-TEQ concentration. The $\sum$ PBDF concentrations were higher than that of $\sum$ PBDDs and all the $\sum$ PBDDs/ $\sum$ PBDFs ratios were $<1$. For some samples, the concentrations of 2,3,7,8-substituted PBDD/Fs in Beijing air in winter exceeded the ambient air standards in some countries, such as, Japan: 600 fg I-TEQ $\mathrm{m}^{-3}$ (http://www.env.go.jp/en/air/aq/aq.html), but in summer the concentrations were below $600 \mathrm{fg} \mathrm{I}^{-T E Q ~ \mathrm{~m}^{-3}}$.

\subsection{Spatial variation}

As shown in Fig. 1, the sampling sites could be divided into different functional zones. Fig. 2 compared the PBDD/Fs homolog groups in the six sites during sampling periods.

Site CQ was residential area and site TT was an urban resort area, but the concentration of PBDD/Fs at these two sites were not different from other sampling sites. This indicated that PBDD/Fs came from the same sources, such as heavy traffic.

Site XS was in Shijingshan district where Capital Iron and Steel Company and Babaoshan funeral parlor were located. Previous research indicated that the concentration of PCBs in this district was two times higher than the background (Sun et al., 2009). But in 2008 , when the steel factory was moved out of city, the concentration of PBDD/Fs in this study was comparable to other sample sites, which indicated the air quality improved since 2008 . When $\mathrm{PCDD} / \mathrm{Fs}$ in the atmosphere within the Babaoshan funeral parlor region were analyzed in November 2010, the I-TEQ concentration ranged $390 \mathrm{fg}$ I-TEQ $\mathrm{m}^{-3}-520 \mathrm{fg}$ I-TEQ $\mathrm{m}^{-3}$. The sampling period and meteorological conditions corresponded to this study in November 2011, and confirmed Babaoshan funeral parlor had no significant influence on the air.

Site DS was about $7 \mathrm{~km}$ from the municipal solid waste incinerator (MSWI). The concentration of PCDD/Fs in the exhaust was $0.04 \mathrm{ng}$ I-TEQ $\mathrm{m}^{-3}$, and was below the European Union limit $\left(0.10 \mathrm{ng}\right.$ I-TEQ $\left.\mathrm{m}^{-3}\right)$, which suggests the MSWI had limited influence on the surrounding air. This deduction was also corroborated
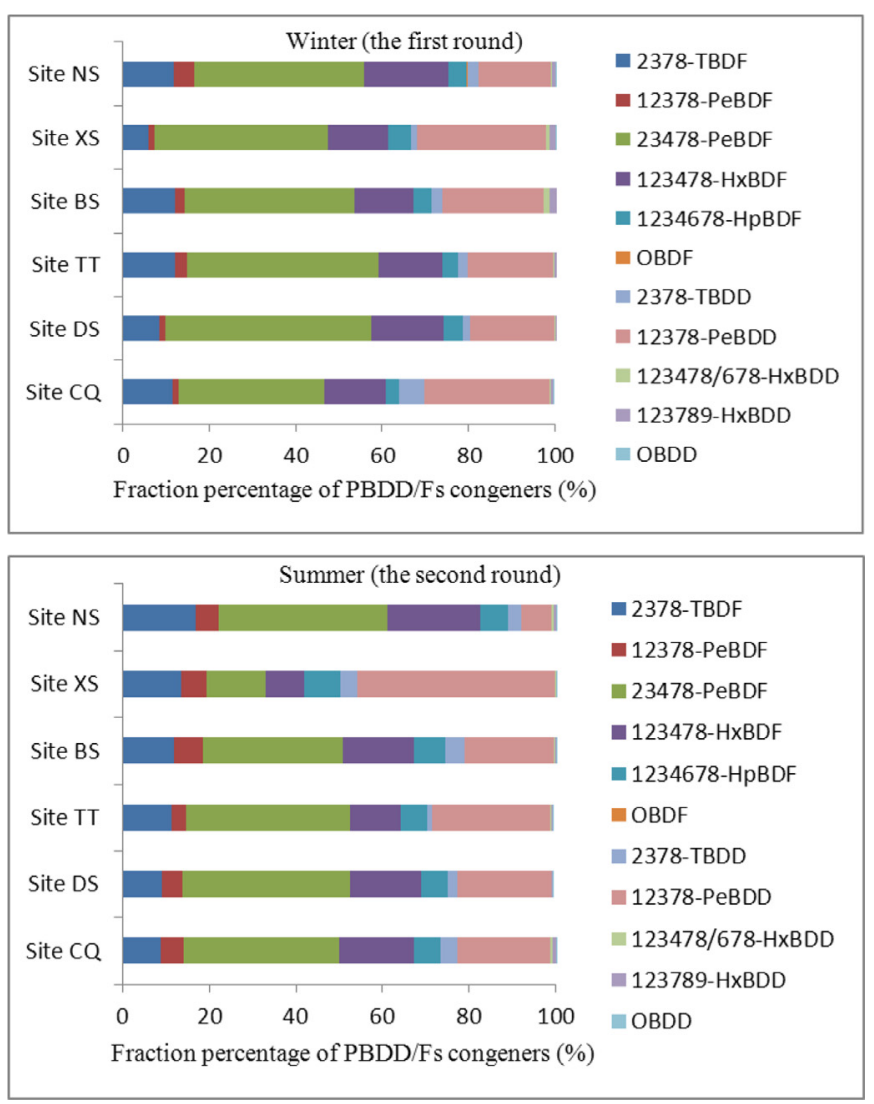

Fig. 3. Relative percentages of $\mathrm{PBDD} / \mathrm{Fs}$ congeners in the six sites in winter and summer (I-TEQ concentration).

by comparing the homolog profiles between the flue gas and ambient air samples.

In conclusion, there was no major industrial activity in Beijing city after 2008. Moreover, the air circulation in this area is typically
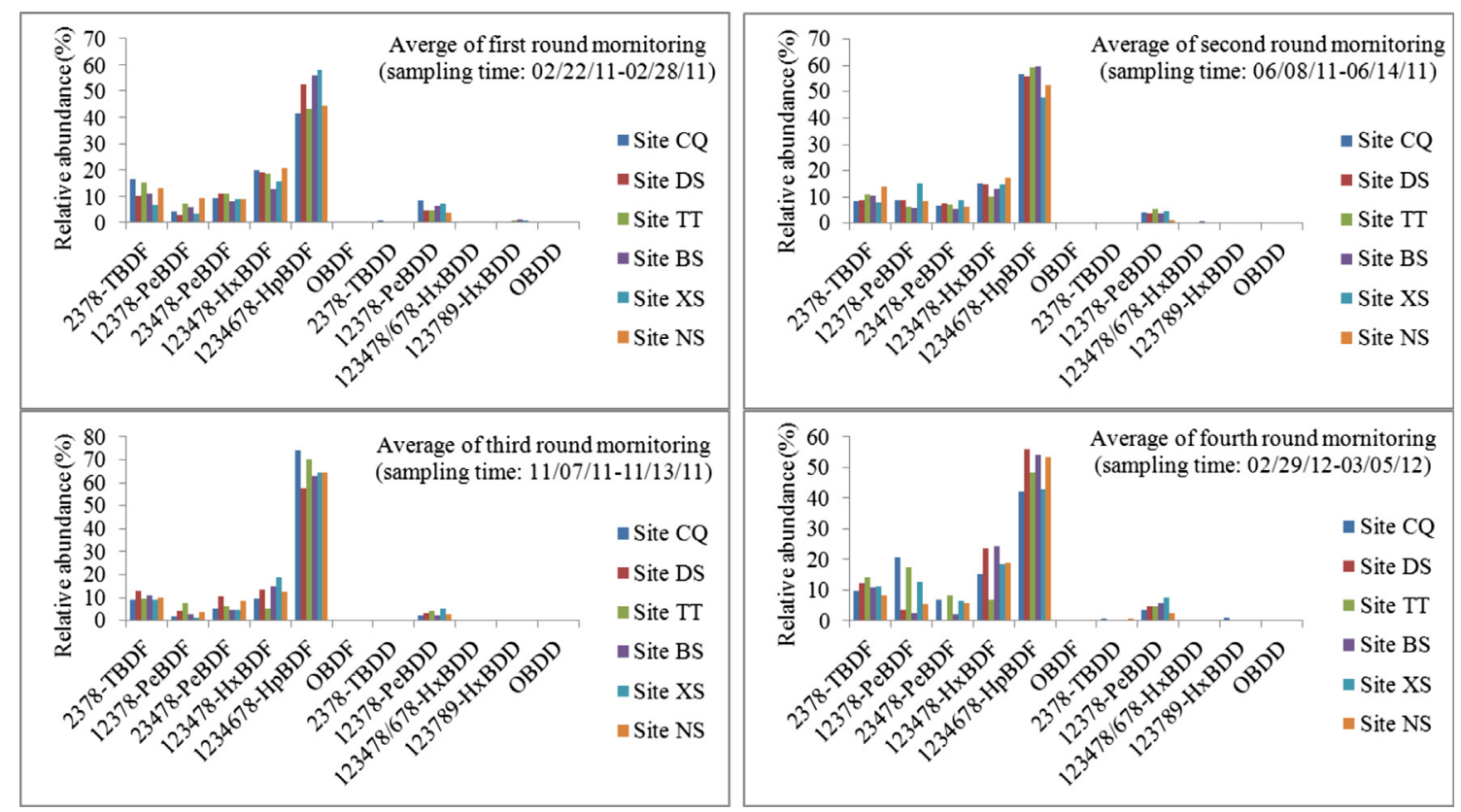

Fig. 2. Comparison of the PBDD/Fs congeners in the six sites during sampling periods (mass concentration). 
Table 2

Inhalation risk evaluation of PBDD/Fs for the six sampling sites in winter (February 22-28, 2011) and in summer (June 8-14, 2011) in Beijing, China.

\begin{tabular}{|c|c|c|c|c|c|c|}
\hline \multirow[t]{3}{*}{ Sampling sites } & \multicolumn{2}{|c|}{ PBDD/Fs TEQ (fg I-TEQ $\mathrm{m}^{-3}$ ) } & \multicolumn{4}{|c|}{ Inhalation exposure dose (fg I-TEQ kg ${ }^{-1}$ day $^{-1}$ ) } \\
\hline & \multirow[t]{2}{*}{ Winter } & \multirow[t]{2}{*}{ Summer } & \multicolumn{2}{|c|}{ Winter } & \multicolumn{2}{|c|}{ Summer } \\
\hline & & & Adult & Children & Adult & Children \\
\hline XS & 200 & 80 & 43 & 76 & 17 & 30 \\
\hline DS & 370 & 80 & 80 & 142 & 18 & 32 \\
\hline TT & 180 & 120 & 39 & 69 & 25 & 44 \\
\hline BS & 290 & 73.3 & 63 & 112 & 15.7 & 27.8 \\
\hline XS & 640 & 50 & 138 & 245 & 10 & 18 \\
\hline NS & 240 & 160 & 52 & 92 & 33 & 59 \\
\hline
\end{tabular}

quick, which facilitates the mixing of ambient pollutants, and thus the concentration and congener profiles for PBDD/Fs in six functional zones show similar characteristics in the same sampling periods.

\subsection{Seasonal variation}

The concentration and profiles of PBDD/Fs in the atmosphere are expected to vary with the season because there were different influences in different seasons, and the conditions for dispersion were also different. Spring and autumn were short, so this paper only compared the PBDD/Fs in winter (February 22-28, 2011, heating period) and in summer (June 8-14, 2011, non-heating period) (Fig. 3).

Seasonal variations were observed in this study. Higher PBDD/F concentrations in winter and lower levels in summer were found, and the ratios of total $\sum$ PBDD/ $\sum$ PBDF in winter and summer were 0.06-0.14 as shown in Supplementary information Table S1. PBDD and PBDF congener distributions were quite different in different seasons. For PBDDs, higher brominated congeners, such as, 1,2,3,7,8,9-HxBDD could be detected in winter, but not in summer. Among the six PBDD congeners, only 2,3,7,8-TBDD and 1,2,3,7,8PeBDD were detected in both winter and summer, but for PBDFs, all congeners could be detected except for OBDFs. Domestic heating in winter might contribute to the higher PBDD/F concentrations. The rate of photolysis for PBDD/Fs is more rapid than that of their chlorinated analogs, especially for more highly brominated PBDD/ Fs congeners, and half-lives are on the order of hours, based on studies of dust particles under sunlight (WHO, 2005). Thus, photolysis is likely one of the most important factors influencing $\mathrm{PBDD} / \mathrm{F}$ atmospheric levels in different seasons. A very high rate of photodegradation results in a great loss of PBDD/Fs in summer. Therefore, atmospheric PBDD/F concentrations at six sample sites were much higher in winter than in summer.

\subsection{Inhalation risk assessment}

Direct inhalation of atmospheric pollutants may be a pathway of exposure to PBDD/Fs, thus emphasizing the need to evaluate the chemical risk posed to humans by daily respiration. We calculated the average daily intake of TEQs per unit body weight with the assumption that individuals were exposed to polluted air $24 \mathrm{~h} \mathrm{day}^{-1}$ and that indoor air pollution was equal to outdoor air pollution. Daily PBDD/Fs exposure doses were computed using the following equation:

$\operatorname{Inh}=\frac{t_{\mathrm{f}} V_{\mathrm{r}} f_{\mathrm{r}} C_{\text {air }}}{\mathrm{BW}}$

Inh is the inhalation exposure in pg I-TEQ $\mathrm{kg}^{-1} \mathrm{day}^{-1}, t_{\mathrm{f}}$ is the exposed time fraction and was assumed conservatively as $1, V_{\mathrm{r}}$ is the ventilation rate with a value of $20 \mathrm{~m}^{3} \mathrm{day}^{-1}$ for adults and
$7.6 \mathrm{~m}^{3}$ day $^{-1}$ for children, $f_{\mathrm{r}}$ is the alveolar fraction retained in the lungs, with a value of 0.75 for both adults and children, $C_{\mathrm{air}}$ is the average air concentration of dioxin in pg I-TEQ $\mathrm{m}^{-3}, \mathrm{BW}$ is the body weight (70 kg for adults and $15 \mathrm{~kg}$ for children) (Yu et al., 2006).

Table 2 lists the estimated daily intakes of PBDD/Fs for human and children by inhalation in winter and summer. As can be seen, residents in six sampling sites in winter were exposed to PBDD/Fs with the daily inhalation doses being 39-138 fg I-TEQ $\mathrm{kg}^{-1}$ day $^{-1}$ for adult and 69-245 fg TEQ $\mathrm{kg}^{-1} \mathrm{day}^{-1}$ for children, but in summer, the values were $10-33$ for adults and $18-59$ for children. From comparison with other cities, the exposure values were similar with Guangzhou (Li et al., 2011) but higher than Shanghai (Li et al., 2008) in winter, and lower than both Shanghai and Guangzhou in summer. There are still no reference values for the percentage of inhalation intake dose in the total daily intake of PBDD/Fs up to now, so we refer to tolerable daily intake (TDI) of PCDD/Fs suggested by WHO in 1998. The WHO European Centre for Environment and Health recommended a TDI of 1000-4000 fg of WHOTEQ $\mathrm{kg}^{-1}$ of body weight (including the WHO-12 PCBs) in 1998 (WHO, 1998a,b). In previous studies, it was estimated that $>90 \%$ of exposure of the general population to PCDD/Fs occurs through diet, and the inhalation intake doses of PCDD/Fs have been reported contributing approximately $2.61 \%$ to the total daily intake (Yu et al., 2006). The daily intakes by inhalation for citizen in Beijing in this study were comparable with the TDI. We cannot give precise total daily PBDD/F intake doses of Beijing citizens, however, according to our results of Inhalation, we could infer that the TDI of residents in Beijing were considerably high in winter and low in summer.

\section{Conclusion}

In this study, the concentrations of $\mathrm{PBDD} / \mathrm{Fs}$ were comparable or lower than other Chinese cities being reported, but higher than some European and American cities. The dominant contributor to total I-TEQ value is 2,3,4,7,8-PeBDF, with an average contribution of $35 \%$. Since 2008, there is little industrial activity in Beijing, and thus spatial variation was not obvious. Higher concentrations were found in winter and lower concentrations were found in summer, so seasonal variation does exist. The daily intakes by inhalation for citizens in Beijing were considerably high in winter. The data in this study is still insufficient to represent other cities in China, so more monitoring programs and studies, in which PBDD/Fs are included, should be carried out in China.

\section{Acknowledgments}

This works was supported by "State Environmental Protection Administration, research and public service industry, a special (Grant No. 201209019, and Grant No. 201309095)". The author also appreciated the assistance of our colleagues for their help in sampling and analyzing. 


\section{Appendix A. Supplementary information}

Supplementary information related to this article can be found at http://dx.doi.org/10.1016/j.atmosenv.2014.06.041.

\section{References}

Alcock, R.E., Behnisch, P.A., Jones, K.C., Hagenmaier, H., 1998. Dioxin-like PCBs in the environment - human exposure and the significance of sources. Chemosphere 31, 1457-1472.

Ashizuka, Y. Nakagawa, R., Hori, T., Yasutake, D., Tobiishi, K., Sasaki, K., 2008. Determination of brominated flame retardants and brominated dioxins in fish collected from three regions of Japan. Mol. Nutr. Food Res. 52, 273-283.

Choi, J.W., Fujimaki, S., Kitamura, K., Hashimoto, S., Ito, H., Suzuki, N., Sakai, S., Morita, M., 2003a. Polybrominated dibenzo-p-dioxins, dibenzofurans, and diphenyl ethers in Japanese human adipose tissue. Environ. Sci. Technol. 37, 817-821.

Choi, J.W., Onodera, J., Kitamura, K., Hashimoto, S., Ito, H., Suzuki, N., Sakai, S. Morita, M., 2003b. Modified clean-up for PBDD, PBDF and PBDE with an active carbon column - its application to sediments. Chemosphere 53, 637-643.

Fernandes, A. Dicks, P., Mortimer, D., Gem, M., Smith, F., Ield, M.D., White, S. Rose, M., 2008. Brominated and chlorinated dioxins, PCBs and brominated flame retardants in Scottish shellfish: methodology, occurrence and human dietary exposure. Mol. Nutr. Food Res. 52, 238-249.

Hagberg, J., Bavel, B.V., Löthgren, C.J., Lindström, G., 2005. Occurrence and levels of PCDD/Fs and PBDD/Fs in two Swedish lake sediments. Organohalog. Compd., 2030-2032.

Hanari, N., Kannan, K., Miyake, Y., Okazawa, T., Kodavanti, P.R.S., Aldous, K.M., Yamashita, N., 2006. Occurrence of polybrominated biphenyls, polybrominated dibenzo-p-dioxins, and polybrominated dibenzofurans as impurities in commercial polybrominated diphenyl ether mixtures. Environ. Sci. Technol. 40, 4400-4405.

Hayakawa, K., Takatsuki, H., Watanabe, I., Sakai, S., 2004. Polybrominated diphenyl ethers (PBDEs), polybrominated dibenzop-dioxins/dibenzofurans (PBDD/Fs) and monobromo-polydibenzo-p-dioxins/dibenzofurans (MoBPXDD/Fs) in the atmosphere and bulk deposition in Kyoto, Japan. Chemosphere 57, 343-356.

In, H.J., Park, S.U., 2003. The soil partical size dependent emission parameterization for and asian dust (Yellow sand) observed in Korea in April 2002. Atmos. Environ. 37, 4625-4636.

Li, H.R., Feng, J.L., Sheng, G.Y., Lu, S.L., Fu, J.M., Peng, P.A., Ren, M., 2008. The PCDD/F and PBDD/F pollution in the ambient atmosphere of Shanghai, China. Chemosphere 70, 576-583.

Li, H.R., Yu, L.P., Sheng, G.Y., Fu, J.M., Peng, P.A., 2007. Severe PCDD/F and PBDD/F pollution in air around an electronic waste dismantling area in China. Environ. Sci. Technol. 41, 5641-5646.

Li, H.R., Zhou, L., Mo, L.G., Peng, P.A., Sheng G.Y., Fu, J.M., Yu, Z.O. 2011. Levels and congener profiles of particle-bound polybrominated dibenzo-p-dioxins/furans (PBDD/Fs) in ambient air around Guangzhou, China. Bull. Environ. Contam. Toxicol. 87, 184-189.

Lohmann, R., Ockenden, W.A., Shears, J., Jones, K.C., 2001. Atmospheric distribution of polychlorinated dibenzo-p-dioxins, dibenzofurans (PCDD/Fs), and nonorthobiphenyls (PCBs) along a north-south Atlantic transect. Environ. Sci. Technol. 35, 4046-4053.

Mari, M., Nadal, M., Schuhmacher, M., Domingo, J.L., 2008. Monitoring PCDD/Fs, PCBs and metals in the ambient air of an industrial area of Catalonia, Spain. Chemosphere 73, 990-998.

Nomura, T., Tanagi, T., Fukuzawa, E., Kono, Y., Komatsu, K., Morita, M., 2007. Brominated dioxins and PBDEs in diet samples collected from FY2002 and FY2005 in Japan. Organohalog. Compd. 69, 2773-2776.
Ohta, S., Nakao, T., Nishimura, H., Okumura, T., Aozasa, O., Miyata, H., 2002 Contamination levels of PBDEs, TBBPA, PCDDs/DFs, PBDDs/DFs, and PXDDs/Fs in the environment of Japan. Organohalog. Compd. 57, 57-60.

Sakai, S., Watanabe, J., Honda, Y., Takatsuki, H., Aoki, I., Futamatsu, M., Shiozaki, K. 2001. Combustion of brominated flame retardants and behavior of its byproducts. Chemosphere 42, 519-531.

Schüler, D., Jager, J., 2004. Formation of chlorinated and brominated dioxins and other organohalogen compounds at the pilot incineration plant VERONA. Chemosphere 54, 49-59.

Schwind, K.H., Hosseinpour, J., Thoma, H., 1988. Brominated/chlorinated dibenzo-pdioxins and dibenzofurans. Chemosphere 17, 1875-1884.

Shih, M., Lee, W.J., Shih, T.S., Huang, S.L., Chang-Chien, G.P., Wang, L.C., 2006 Characterization of dibenzo-p-dioxins and dibenzofurans (PCDD/Fs) in the atmosphere of different workplaces of a sinter plant. Sci. Total Environ. 366, 197-205.

Sovocool, G.W., Donnelly, J.R., Munslow, W.D., Vonnahme, T.L., Nunn, N.J., Tondeur, Y., Mitchum, R.K., 1989. Analysis of municipal incinerator fly ash for bromo- and bromochloro-dioxins, dibenzofurans, and related compounds. Chemosphere 18, 193-200.

Sun, J.L., Liu, D.M., Zhang, Q.H., Yang, X., 2009. Pollution level and spatial distribution of polychlorinated biphenyls from atmospheric matter PM2.5 in Beijing. Geoscience 23, 378-384.

Tasaki, T., Takasuga, T., Sako, M., Sakai, S., 2004. Substance flow analysis of brominated flame retardants and related compounds in waste TV sets in Japan. Waste Manag. 24, 571-580.

Thoma, H., Hauschulz, G., Knorr, E., Hutzinger, O., 1987. Polybrominated dibenzofurans (PBDFs) and dibenzodioxins (PBDDs) from the pyrolysis of some flame retardants neat brominated diphenylethers, biphenyl and plastic mixtures of these compounds. Chemosphere 16, 277-285.

Watanabe, I., Kawano, M., Tatsukawa, R., 1995. Polybrominated and mixed polybromo/chlorinated dibenzo-p-dioxins and -dibenzofurans in the Japanese environment. Organohalog. Compd. 24, 337-340.

Watanabe, I., Kawano, M., Wang, Y., Chen, Y., Tatsukawa, R., 1992. Polybrominated dibenzo-p-dioxins (PBDDs) and -dibenzofurans (PBDFs) in atmospheric air in Taiwan and Japan. Organohalog. Compd. 9, 309-312.

Wang, L.C., Chang-Chien, G.P., 2007. Characterizing the emissions of polybrominated dibenzo-p-dioxins and dibenzofurans from municipal and industrial waste incinerators. Environ. Sci. Technol. 41, 1159-1165.

Wang, L.C., Tsai, C.H., Chang-Chien, G.P., Hung, C.H., 2008. Characterization of polybrominated dibenzo-p-dioxins and dibenzofurans in different atmospheric environments. Environ. Sci. Technol. 42, 75-80.

Weber, R., Kuch, B., 2003. Relevance of BFRs and thermal conditions on the formation pathways of brominated and brominated-chlorinated dibenzodioxins and dibenzofurans. Environ. Int. 29, 699-710.

WHO, 1994. Polybrominated diphenylethers. Environ. Health Criteria 162.

WHO, 1998a. Assessment of the Health Risk of Dioxins: Reevaluation of the Tolerable Daily Intake (TDI). WHO European Centre for Environment and Health International Programme on Chemical Safety, Geneva. http://www.who.int/ ipcs/publications/en/exe-sum-final.pdf.

WHO, 1998b. Polybrominated dibenzo-p-dioxins and dibenzofurans. Environ. Health Criteria 205. http://www.inchem.org/documents/ehc/ehc205.htm.

WHO, 2005. Polybrominated dibenzo-p-dioxins and dibenzofurans. Environ. Health Criteria 205.

Yu, L.P., Mai, B.X., Meng, X.Z., Bi, X.H., Sheng, G.Y., Fu, J.M., Peng, P.A., 2006. Particlebound polychlorinated dibenzo-p-dioxins and dibenzofurans in the atmosphere of Guangzhou, China. Atmos. Environ. 40, 96-108.

Zober, M.A., Ott, M.G., Papke, O., Senft, K., Germann, C., 1992. Morbidity study of extruder personnel with potential exposure to brominated dioxins and furans. I Results of blood monitoring and immunological tests. Br. J. Ind. Med. 49 $532-544$. 